\title{
Res Cogitans
}

Volume 6 | Issue 1

Article 3

$5-29-2015$

\section{Climbing to Consciousness: The Mind-Body Problem and the Computational Order}

Trent Eady

McGill University

Follow this and additional works at: http://commons.pacificu.edu/rescogitans

Part of the Philosophy Commons

\section{Recommended Citation}

Eady, Trent (2015) "Climbing to Consciousness: The Mind-Body Problem and the Computational Order," Res Cogitans: Vol. 6: Iss. 1, Article 3. http:dx.doi.org/10.7710/2155-4838.1120

This Article is brought to you for free and open access by CommonKnowledge. It has been accepted for inclusion in Res Cogitans by an authorized administrator of CommonKnowledge. For more information, please contact gilmani@pacificu.edu. 


\title{
Climbing to Consciousness: The Mind-Body Problem and the Computational Order
}

\section{Trent Eady \\ McGill University}

Published online: May 292015

(C) Trent Eady 2015

\begin{abstract}
In his book The Structure of Behavior, the philosopher Maurice Merleau-Ponty proposes a solution to the mind-body problem. Merleau-Ponty argues that there is a nested hierarchy of three orders-the physical order, the biological order, and the mental order-in which each lower order composes each higher order. Through the structuration or organization of a lower order, a higher order is created. MerleauPonty's solution is promising, but it leaves an explanatory chasm between the biological order and the mental order that cannot be crossed without introducing an intermediary order. I propose just that: the addition of a fourth order — the computational order — to bridge the chasm.
\end{abstract}

In his book The Structure of Behavior, Maurice Merleau-Ponty develops a view of what constitutes the mental, paying particular attention to the mind-body problem, that is, the question of what relation the mental has to the physical (Merleau-Ponty 1967: 202). Merleau-Ponty is not satisfied with what he calls the classical solutions to the mindbody problem and attempts to formulate his own solution. The classical solutions are those proposed by two opposing camps that from Merleau-Ponty's perspective dominate the discourse on mentality. He calls these two camps the "mentalists" and the "materialists", respectively (Merleau-Ponty 1967: 182).

René Descartes is the paradigmatic mentalist. Descartes famously holds that the mental and the physical are two fundamentally different, utterly distinct types of being, or substances. For this reason, Descartes' view is usually called substance dualism. Substance dualism, however, is by no means exhaustive of mentalism. Idealists also fall into the mentalist camp. Merleau-Ponty discusses Immanuel Kant's transcendental idealism in particular. Transcendental idealism is the position that all that we can ever know is what appears to us (phenomena), and we can know nothing of any things in themselves (noumena). 
Materialism, for Merleau-Ponty, includes most notably behaviorism in psychology. There are at least two versions of behaviorism. In the first version, mentality is ignored for methodological reasons. Behavior is not attributed to anything mental. In the second version, the mental is discarded as metaphysical excess. This latter version of behaviorism is a form of eliminative materialism about the mental in general. Both versions favor an understanding of behavior that uses purely physical or physiological language.

Merleau-Ponty is not content to join either the mentalist or the materialist camp. On one hand, he denies that the mental is something over and above the physical or the biological. On his view, the mental does not exist independently from the physical and biological constitution of human beings. Thus, Merleau-Ponty rejects substance dualism. He also rejects transcendental idealism. On Merleau-Ponty's view appearances or phenomena, being mental, are not something over and above the things in themselves, i.e. the physical and the biological. Therefore, knowledge of appearances or phenomena necessarily entails knowledge of the things in themselves.

On the other hand, Merleau-Ponty enthusiastically affirms the existence of consciousness, thus rejecting the eliminative materialist version of behaviorism and other forms of eliminative materialism about the mental in general. He also rejects the methodological version of behaviorism on the grounds that the observation of behavior (itself a behavior) requires a conscious observer. The removed, "third-person" perspective of science is founded in the involved, first-person perspective of consciousness.

Merleau-Ponty's proposal avoids both the mentalists' and the materialists' solutions to the mind-body problem by positing a compositional or hierarchical relation between the mental and the physical. Crucially, it is not a direct relation, but a nested relation in which the biological (or "vital", as Merleau-Ponty calls it) takes an intervening place between the mental and the physical. To put it more accurately, then, Merleau-Ponty posits a compositional or hierarchical relation between the mental, the biological, and the physical (in descending order).

In The Structure of Behavior, Merleau-Ponty introduces the notion of three orders. He posits a physical order, a biological order that is higher than and "enrooted in" the physical order, and a mental order which is higher than and rooted in the biological order (Merleau-Ponty 1967: 184). Importantly, Merleau-Ponty rejects the idea that the mental is something that is "added to" the lower orders (Merleau-Ponty 1967: 181). The three orders are not layers that are stacked on top of each other, such that they constitute three different parts of a human being. For Merleau-Ponty, the relation of a lower order to a higher order is the relation of the "partial to the total" (Merleau-Ponty 
1967: 180). The relation, then, is not only hierarchical but also compositional. That is, a lower order composes a higher order as parts compose a whole.

Although there is an intervening biological order, Merleau-Ponty's claim is nevertheless that the mental is ultimately composed of the physical as a whole is composed of parts. This claim must confront a serious challenge. It is normally thought that a physical thing, on its own, is just mindless, meaningless matter. A quark, an electron, an atom, a molecule, a birthday cake, a watermelon, or a mound of gravel seems as devoid of mentality as anything could be. Moreover, wholes composed of many physical parts seem equally unconscious as any other physical thing. For example, an airplane is made of thousands of physical parts, and yet the mental seems as far out of its reach as it is for a mound of gravel. Its lack of mentality cannot be explained by positing that it has an insufficient number of parts, since it seems that the addition of more parts to an airplane would result only in more of the same. For example, we can imagine lengthening the fuselage and adding seats, lights, baggage containers, windows, engines, and wings. We can imagine doing this until there is no room left on the planet for such an aircraft, or even until there is no room for it in the known universe. Even if we could add parts unboundedly towards infinity, it seems that no number of them would ever suffice to constitute mentality. Whether a physical thing is an ordinary object or an arbitrarily large whole makes no difference. Physical things, it seems, are mindless.

Merleau-Ponty claims that the mental is ultimately composed of the physical, yet the physical seems only to amount to mindless, meaningless matter. One might be tempted to interpret Merleau-Ponty's view, then, as a form of panpsychism that holds that all physical things, contrary to what it seems, do in fact have some amount of mentality. In this case, the impression that atoms, mounds of gravel, or airplanes are entirely devoid of mentality would just be wrong. However, since Merleau-Ponty dismisses “animism” this cannot be his view (Merleau-Ponty 1967: 161). How else could the physical order ultimately compose the mental order?

Merleau-Ponty answers that the biological order is a "structuration" of the physical order, and the mental order is in turn a structuration of the biological order (MerleauPonty 1967: 184). On Merleau-Ponty's view, then, the mental and the physical are not different substances or different "powers of being" (Merleau-Ponty 1967: 184). Even by using the word "order" to describe the mental and the physical, Merleau-Ponty evokes the idea of structure or organization. Two orders of things can be different and yet the things that they order can be exactly the same. If the mental is the mental order, as Merleau-Ponty claims, then the mental is ultimately composed of the same kinds of things as inanimate physical objects. Merleau-Ponty's view entails that at the fundamental level there is nothing that the mental has that the physical does not. For Merleau-Ponty, then, the mental is ultimately, through the biological, a certain 
organization of the physical. All that is required for consciousness, on his view, is for otherwise mindless, meaningless matter to be organized in the right way. To claim that structuration or organization can constitute consciousness out of the merely physical is to attribute to it an immense capability. In order to investigate whether it indeed has that capability, we must attempt to climb the ladder from the physical order to the mental order rung by rung.

The physical order can roughly be said to include matter, energy, and physical forces. The contribution of the physical to the climb is that the physical is not a void. Physical existence is a kind of existence. As such, the physical order surmounts for us the problem that nothingness would pose. Moreover, physical existence is not chaotic, but ordered. The physical order, then, introduces existence and order, two necessary foundations for the mental.

The structuration of the physical is what gives rise to the biological, without the aid of a new substance or an élan vital. The organization of the physical transforms inert matter pushed around by physical forces into a new category of things that have functions. The heart does not merely passively allow physical forces to push blood through it; it is the organization of those forces in such a way that it is a thing that pushes blood. As Merleau-Ponty writes, the higher order "eliminate[s] the autonomy" of the lower order and introduces a new logic (Merleau-Ponty 1967: 180). Through the organization of the physical, there exist things-organisms - that actively maintain their own integrity, through homeostasis and other forms of self-preservation. Another thing that organisms do is internalize their encounters with things in the world. Organisms have parts whose function is to store traces of these encounters for future use in modulating function. That is, in an organism there exists a structured collection of the physical that contains some information about something that happened to that organism. We can view this internalization of information about events in the world either as intentionality proper or as proto-intentionality. Either way, it is something new and important that the biological order introduces to the physical order. The biological order, then, contributes function and intentionality or proto-intentionality to the climb to consciousness.

Examination of human beings' biological constitution in relation to mentality usually entails particularly intensive examination of the nervous system and, more specifically, the brain. The brain is typically understood not in the terms of the physical order but in terms of the biological order. It is not inert matter that is passively pushed around by physical forces. To view it as such would make its activity incomprehensible. Rather, the brain is viewed as something that pushes around matter. It is a functional configuration of ultimately physical parts. A neuron is understood as a cell that sends and receives electrochemical signals. Certain chemicals in the brain are not understood solely in terms of their physical properties but primarily by their role in the transmission of signals: they are called "neurotransmitters." Moreover, these signals are 
understood as more than just electrochemical events the brain; they can be understood in terms of their abstract properties. That is, the sending of signals can be understood as the transmission of information. The brain is not like the heart, which simply pumps blood. The brain does not simply pump electrochemistry. The heart's activity is not about anything, but the brain's biological activity is rich with information about the body, the world, and itself. That is, the brain's activity exhibits intentionality, or at least proto-intentionality. If information of this sort can ultimately compose the sort of intentionality that conscious human beings experience, then it is the informationbearing and information-transmitting capabilities of the brain that will lead from the biological order to the mental order.

However, the way from this point to the mental order is not so clear. Neuroscience often produces correlations between the activity of certain areas of the brain and certain kinds of mental activity. For example, the activity of the hippocampus is correlated with remembering the spatial layout of familiar places. However, such correlations do not explain in any deep way how kinds of mental activity are rooted in the biological constitution of their associated brain regions. Standing firmly upon the biological order, the top rung of the ladder remains out of reach. Can we only grasp for air, then, or might we find something solid above us?

Faced with a version of this problem, the philosopher Daniel C. Dennett argues that the "concepts of computer science provide the crutches of imagination we need" in order to find the way from "our brains" to "our phenomenology" (Dennett 1991: 433). Computer science, strictly speaking, is too limited in scope. That is, if computer science is strictly the study of the kind of computer that is manufactured by humans, then it cannot be applied directly to the problem at hand. Instead, what is needed is a broader concept of computation by analogy to human-made computers. The concept of computation did originate from human-made computers. However, its scope can greatly exceed them. Computation has been attributed to entities as diverse as cell membranes and black holes. The notion of computation need not have any rigid boundaries in its scope. The concept of computation, in this broader sense, can be used in understanding the relation between the biological and the mental.

Previously, emphasis was placed on the information-bearing and informationtransmitting capabilities of the brain. Applying the concept of computation to the brain adds information processing to its capabilities. Information processing begins with an informational situation, then attempts to reach a certain outcome, an outcome within a certain range, an outcome that satisfies one or more of a polythetic set of criteria, or an outcome that satisfies to a certain degree a set of standards too complex to describe briefly. These are only a few examples, and even these can be further complicated. For example, what qualifies as satisfaction or as a certain degree of satisfaction can itself rely on a set of standards that defy brief description. Satisfaction of the set of standards 
for satisfaction can itself rely another set of standards, and so on. Any criterion in a polythetic set can itself be a range, or a nested polythetic set, a range of polythetic sets, or a polythetic set of ranges. There are boundless possibilities of this kind in terms of what outcome a certain instance of information processing might attempt to reach, and for any one of these possibilities there may be countless possible ways to reach it. Here, again, information processing admits of recursion. An instance of information processing must use one or another way to attempt to reach its goal, and there may be many methods to select which way it will use. It must, in that case, use one or another such method, and again there may be many methods for selecting one, and so on. There can be an indefinite number of recursive levels of this sort for any aspect of information processing. Information processing, then, should not be imagined as simply deductive or arithmetic. In fact, it is as complex and labyrinthine as anything that can be imagined. Information processing opens up a field of possibility unprecedented in the biological order or in the physical order.

An individual instance of information processing can be conceived as a unit within a larger system of units. A unit can be considered in isolation, or in the case of an organized collection of units, it can be considered as part of a whole that can itself be conceived as a unit. These units, in turn, can serve as parts in still larger units, and so on. A unit, despite internally being vastly complex, can nonetheless be summed up in terms of what is characteristic about it. For example, we could describe one as a unit that stores and makes available at any time the auditory information of the spoken word "ocean". We could describe another as a unit that stores and makes available at any time the series of muscle movements necessary to utter the word "ocean" aloud. We could describe a third as a unit that stores and makes available the visual information of the written word "ocean", and a fourth as a unit that stores and makes available the series of letters necessary to spell the word "ocean" in writing. Other units could be those that store and make available the conceptual content of the word "ocean", and still others could be those that link "ocean" with all its associations by mediating between all of the previous units and the rest of the entire system of units. Since any organized collection of units can be conceived as a unit, together all of these units can be described as the unit that constitutes the word "ocean". In other words, in an individual, this unit is the word "ocean". In this way, millions or billions of neurons, organized collectively into an information processing system, can give rise to words. Other units, other computational entities, can be identified with entities that exist in the mind. Computation allows abstract entities to exist and to behave according to their own logic, and yet be founded on the biological constitution of the brain. Between the biological order and the mental order, then, I propose an intervening computational order. There is no way to jump directly from the biological to the mental. If there is any hope of climbing the ladder to consciousness, it is through computation. 
How receptive would Merleau-Ponty be to the addition of a computational order to his schema? The computational order matches a description that he gives of the psychological. That is, in the computational order "vital energies are no longer the motor forces of behavior", since information processing is driven by its own goals (Merleau-Ponty 1967: 179). Neurons, the cellular elements of the brain, "have been really integrated into a new whole," into an abstract, computational system (MerleauPonty 1967: 179). The computational order at least meets the requirements for being an order higher than the biological. It is possible that Merleau-Ponty would take issue with focusing on the brain and neglecting the rest of the body. However, this is an easy issue to resolve. Although the brain is the most notable part of the body in terms of computation, it is in fact more accurate to talk about human computation as an activity of the nervous system as a whole. The computational system extends throughout the entire body. Similarly, computation can be said to be, or to include, a reciprocal interaction between the body and the world, whose contents include an immediate physical environment and other human beings, along with their language and culture.

In his later work, Merleau-Ponty proposes his concept of flesh, which in his view underlies both the mental and the physical and thereby reconciles them. This lends credence to the interpretation previously made of his view in The Structure of Behavior that at the fundamental, compositional level, there is no difference between the mental and the physical (although Merleau-Ponty would say that level is the level of flesh, not the physical level). The concept of computation, in an entirely different way, can be used to reconcile the mental and the physical. This is what I have attempted to show in this paper.

The view that in the case of human minds the mental and the physical are both computational does something else besides solve the mind-body problem. It unites the concreteness and ideality of human being. If the computational order underlies the mental order, as I argue, then our concrete sensations and even our experience of embodiment itself are made of information processing. That is, we are bodies made of abstractions.

\section{References}

Daniel, Daniel C. Consciousness Explained. New York: Back Bay Books, 1991.

Merleau-Ponty, Maurice. The Structure of Behaviour. Trans. Fisher. Boston: Beacon Press, 1967. 